\section{Decreased Mortality in Patients With Severe Bronchospasm Associated With SARS-CoV-2: An Alternative to Invasive Mechanical Ventilation}

\author{
Rafael Salazar Sr. ${ }^{1}$, Alejandro Hallo ${ }^{2}$, Sebastian Vasquez ${ }^{1}$, Steffy Reinthaller ${ }^{1}$, Juan Echeverria ${ }^{1}$ \\ 1. Emergency Department, Hospital Pablo Arturo Suárez, Quito, ECU 2. Internal Medicine, Hospital de Especialidad \\ Eugenio Espejo, Quito, ECU
}

Corresponding author: Alejandro Hallo, alejo_h1712@hotmail.com

\begin{abstract}
The number of patients with acute episodes of severe bronchospasm needing intubation and ventilatory support has increased rapidly during the severe acute respiratory syndrome coronavirus 2 (SARS-CoV2) coronavirus disease 2019 (COVID-19) pandemic. Although medical consensus upholds the use of ventilatory support in this pathology, its survival benefits remain unclear. To improve the outcomes and survival rates, a bundle of early respiratory therapy with a pharmacological rescue regimen was provided to four patients with bronchospasm secondary to COVID-19. This therapeutic approach successfully delayed the need for invasive mechanical ventilation for 48 hours and decreased the mortality rate in all cases.
\end{abstract}

Categories: Emergency Medicine, Infectious Disease

Keywords: covid-19 outbreak, covid-19 management, invasive mechanical ventilation

\section{Introduction}

During the coronavirus disease 2019 (COVID-19) pandemic, the number of patients with bronchospasm requiring mechanical ventilation has increased considerably.

The sudden increase in patients needing intubation represents an unprecedented challenge due to limited availability of equipment in poorly prepared health systems [1] and the lack of evidence to support its longterm benefits. According to Lai, $20.1 \%$ of patients with severe acute respiratory syndrome coronavirus 2 (SARS-CoV-2) develop acute respiratory distress syndrome (ARDS) and $9 \%$ require invasive mechanical ventilation (IMV) [2]. Poor response to IMV leads to a mortality rate of $10.4 \%$ at 24 hours and $61 \%$ in the following days in Intensive Care Unit (ICU) stay [3].

The increased mortality in critically ill patients [4], compared with the relatively low mortality rate in the general population [1], has prompted the scientific community to design new therapeutic approaches. Global concern about the pandemic has indeed fueled research for treatments to fight the infection; however, to date, there is no standardized treatment [5] and the process to develop a successful treatment might take months [6].

Received 08/01/2020

Review began 09/24/2020

Review ended 10/04/2020

Published 10/06/2020

(c) Copyright 2020

Salazar et al. This is an open access

article distributed under the terms of the Creative Commons Attribution License CC-BY 4.0., which permits unrestricted use, distribution, and reproduction in any medium, provided the original author and source are credited.
We presented four cases in which we used early respiratory therapy and pharmacological approach to successfully address acute episodes of bronchospasm delaying the use of invasive mechanical ventilation 48 hours after the acute episode.

\section{Case Presentation}

\section{Case 1}

A 59-year-old male, COVID-19-positive confirmed with polymerase chain reaction (PCR) assay patient with no significant past medical history came to the Emergency Room (ER) complaining of respiratory distress.

The patient was admitted under suspicion of bronchospasm with preserved acid-base balance [pH: 7.41 (normal range $=7.35-7.45)$, partial pressure of carbon dioxide $\left(\mathrm{PaCO}_{2}\right): 39 \mathrm{mmHg}$ (normal range $=33$ $45 \mathrm{mmHg}$ ), partial pressure of oxygen $\left(\mathrm{PaO}_{2}\right): 55 \mathrm{mmHg}$ (normal range $\left.\left.=75-105 \mathrm{mmHg}\right)\right]$, fraction of inspired oxygen $\left(\mathrm{FiO}_{2}\right)$ of 57 (normal range $=>68 \%$ ), $\mathrm{PaO}_{2} / \mathrm{FiO}_{2}$ was 96 (normal range $\left.=>300\right)$, and oxygen saturation of $88 \%$ associated with SARS-CoV-2 complicated with acute respiratory distress syndrome (ARDS).

On admission, the chest X-ray showed bilateral ground-glass pattern, Radiographic Assessment of Lung Edema (RALE) score 2 (Figure 1) [7]. The patient scored 4 on the Sequential Organ Failure Assessment (SOFA) score and 12 on the Acute Physiology And Chronic Health Evaluation (APACHE) score (Table 1). 


\section{Cureus}
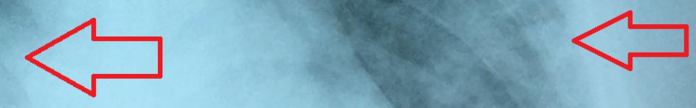

\section{FIGURE 1: Radiographic assessment of lung involvement}

Anteroposterior chest X-ray at the time of acute bronchospasm with Radiographic Assessment of Lung Edema (RALE) score 2

\begin{tabular}{|c|c|c|c|c|c|c|c|c|c|c|c|c|c|c|c|}
\hline Temperature $\left({ }^{\circ} \mathrm{C}\right)$ & MAP & HR & RF & $\mathrm{PaO2}(\mathrm{mmHg})$ & $\mathrm{pH}$ & $\mathrm{Na}(\mathrm{mEq} / \mathrm{L})$ & $K(\mathrm{mEq} / \mathrm{L})$ & Crea (mg/dL) & Hto $(\%)$ & Gcs & $\mathrm{PaO2} / \mathrm{FiO} 2$ & Diuresis & TB (mg/dL) & Platelets $\left(\times 10^{3} / \mu \mathrm{L}\right)$ & Vasoactive \\
\hline 37.2 & 71 & 85 & 30 & 55 & 7.41 & 130.2 & 4.1 & 0.96 & 47.8 & 15 & 96 & 850 & 0.7 & 233000 & NO \\
\hline 36.8 & 80 & 91 & 30 & 65 & 7.34 & 138.7 & 4.5 & 1.04 & 45.4 & 15 & 115 & 1250 & 0.56 & 428000 & NO \\
\hline 36.2 & 63 & 109 & 47 & 32 & 7.26 & 143.4 & 4.08 & 0.56 & 41.7 & 15 & 120 & 1500 & 0.49 & 620000 & NO \\
\hline 36.2 & 65 & 125 & 35 & 71 & 7.35 & 145 & 3.7 & 0.47 & 41.6 & 15 & 180 & 1300 & 0.27 & 399000 & No \\
\hline 37.1 & 62 & 99 & 29 & 63 & 7.39 & 142.5 & 4.9 & 0.58 & 48 & 15 & 104 & 1250 & 0.44 & 296000 & NO \\
\hline 36.3 & 70 & 102 & 35 & 66 & 7.38 & 124.2 & 5.3 & 0.99 & 45 & 15 & 228 & 1000 & 0.61 & 317000 & NO \\
\hline
\end{tabular}

\section{TABLE 1: Vital signs and laboratory workup during the acute episode of bronchospasm.}

MAP: Mean Arterial Blood Pressure. HR: Heart Rate. RF: Respiratory frequency. PaO2: Partial pressure of oxygen. Crea: Creatinine. Hto: Hematocrit. GCS: Glasgow Coma Scale. PaO2/FiO2: arterial oxygen pressure/inspired fraction of oxygen. TB: Total Bilirubin

The initial management comprised placing the patient in the prone position and administering oxygen at high flow through a non-rebreather mask with flow between 10 and 15 liters per minute until reaching $100 \%$ $\mathrm{FiO}_{2}$. Additionally, respiratory therapy consisting of deep inspiration with an inspiratory hold technique was implemented. Epinephrine and magnesium sulfate were administered as a bronchodilator regimen (Table 2). 


\section{Cureus}

Pharmacological treatment

Ipratropium bromide

Adrenalin (1:10000)

Magnesium sulfate
2 puff every 20 minutes for one hour followed by once every 6 hours

$0.03 \mathrm{mg}$ intravenously every 8 hours

2 gr every 8 hours

\section{TABLE 2: Acute pharmacological treatment for acute bronchospasm}

\section{Case 2}

A 59-year-old male COVID-19-positive patient with no significant past medical history came to the ER complaining of respiratory distress. The patient was admitted due to suspected bronchospasm associated with SARS-CoV-2 and later diagnosed with ARDS.

On admission, laboratory and imaging tests showed bilateral ground-glass pattern on chest X-ray and a RALE score of 2 (Figure 2) [7]. The arterial blood gases were within normal limits [pH: 7.35 (normal range = 7.35-7.45), $\mathrm{PaCO}_{2}: 44$ (normal range $=33-45 \mathrm{mmHg}$ ), $\mathrm{PaO}_{2}: 58$ (normal range $=75-105 \mathrm{mmHg}$ ), $\mathrm{FiO}_{2}$ of 40 (normal range $=>68 \%$ ), $\mathrm{PaO}_{2} / \mathrm{FiO}_{2}$ was 115 (normal range $=>300$ ) and an $\mathrm{O}_{2}$ Saturation of $78 \%$. The SOFA score was 3 and APACHE score was 6 (Table 1 ).

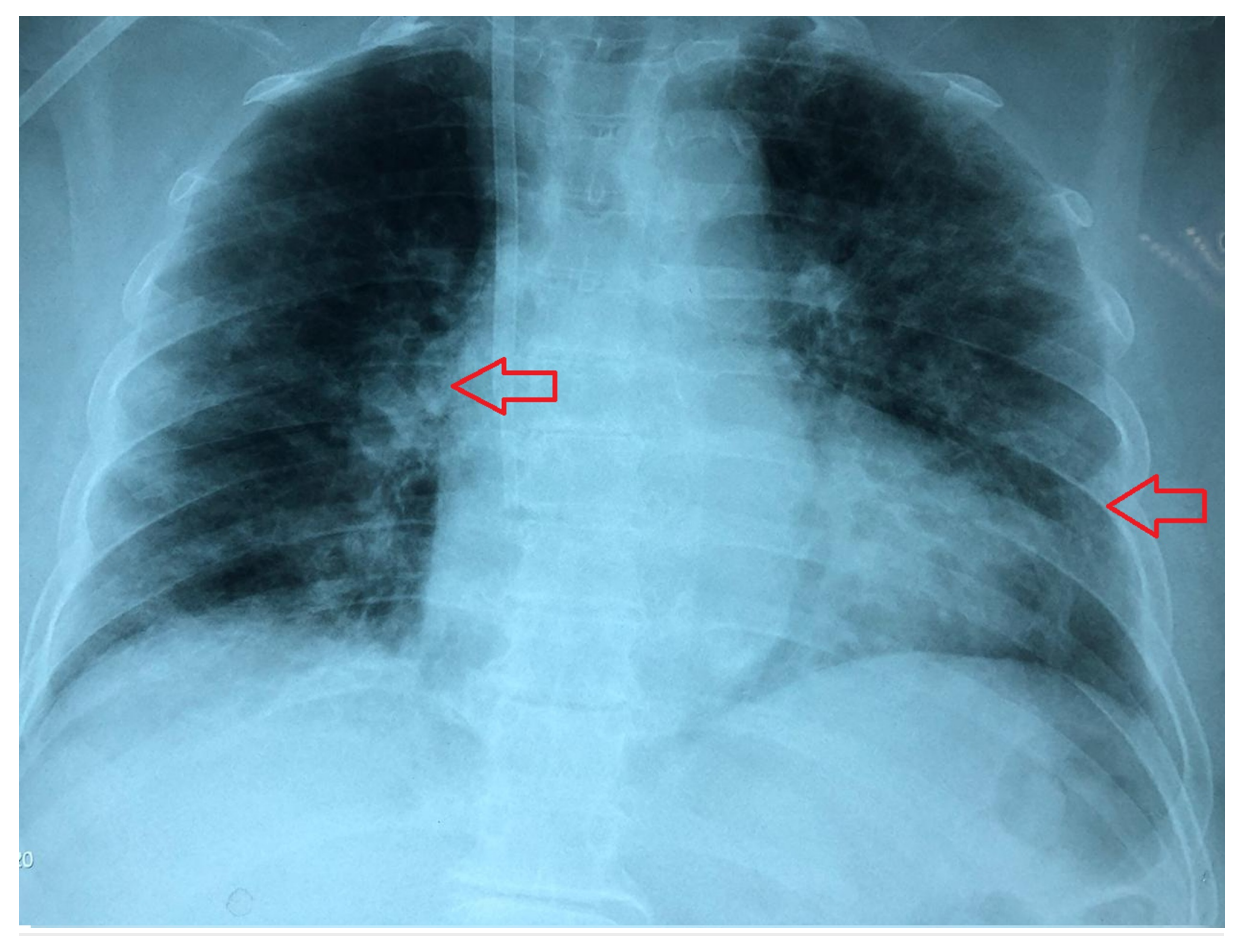

\section{FIGURE 2: Radiographic assessment of lung involvement}

Anteroposterior chest X-ray at the time of acute bronchospasm with Radiographic Assessment of Lung Edema (RALE) score 2

The patient was placed in the prone position and oxygenated at high flow with a non-rebreather mask with flow between 10 and 15 liters per minute until reaching $100 \% \mathrm{FiO}_{2}$. Additionally, respiratory therapy consisting of deep inspiration with an inspiratory hold technique was started. Epinephrine and magnesium sulfate were administered as a bronchodilator regimen (Table 2).

\section{Case 3}

A 33-year-old female patient with morbid obesity was admitted to our hospital due to the risk of COVID-19 related complications. 


\section{Cureus}

The patient was managed with antipyretics during hospitalization. On the third day of admission, she developed severe bronchospasm and was transferred to ICU due to poor ventilatory mechanics with preserved acid-base state $[\mathrm{pH}: 7.35$ (normal range $=7.35-7.45), \mathrm{PaCO}_{2}: 39$ (normal range $=33-45 \mathrm{mmHg}$ ), $\mathrm{PaO}_{2}: 71$ (normal range $\left.=75-105 \mathrm{mmHg}\right)$, $\mathrm{FiO}_{2}$ of 50 (normal range $=>68 \%$ ), $\mathrm{PaO}_{2} / \mathrm{FiO}_{2}$ was 182 (normal range $=>300$ ) and an $\mathrm{O}_{2}$ saturation of $93 \%$ associated with SARS-CoV-2. The patient was diagnosed with ARDS.

The chest X-ray showed bilateral ground-glass pattern, RALE score was 1 (Figure 3) [7]. SOFA score was 3 and APACHE score was 8 (Table 1).

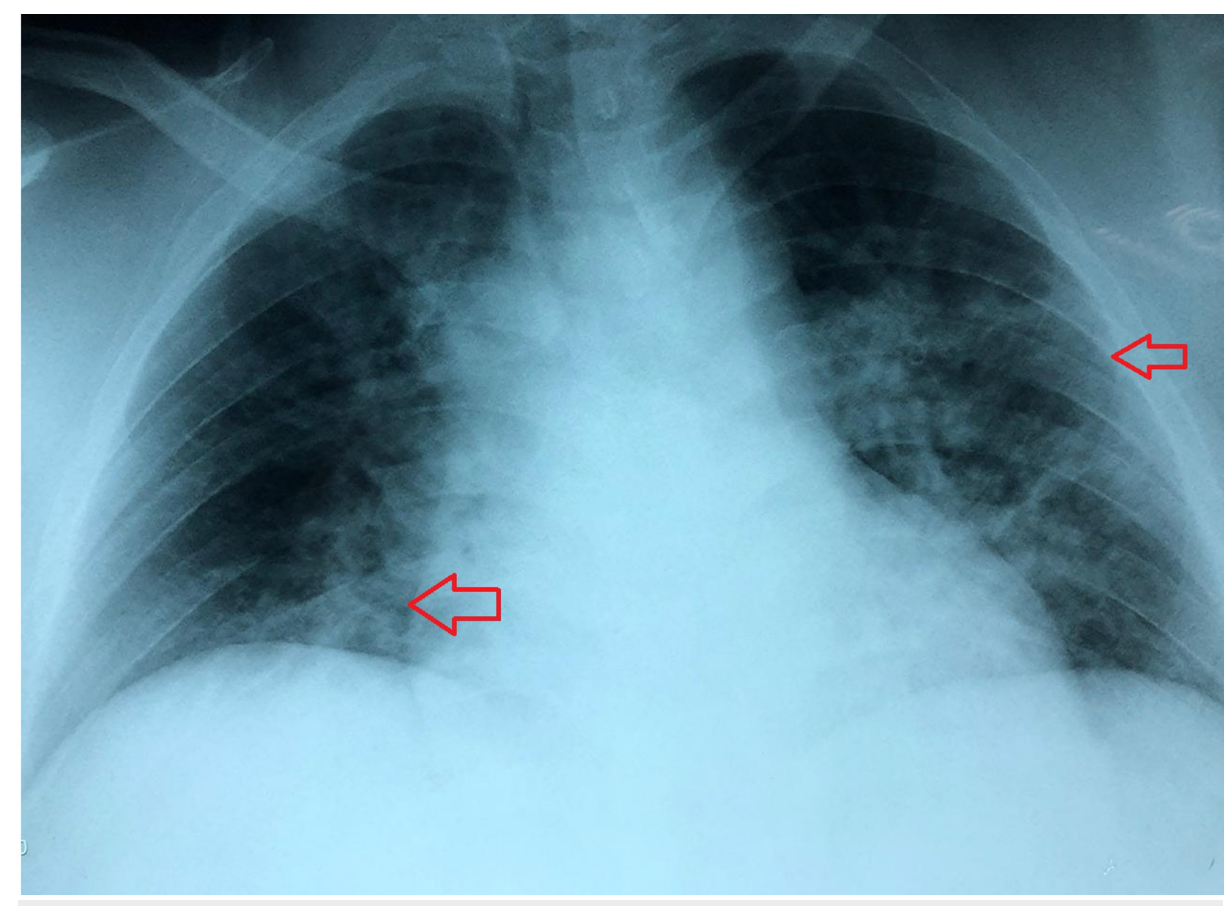

\section{FIGURE 3: Radiographic assessment of lung involvement}

Anteroposterior chest X-ray at the time of acute bronchospasm with Radiographic Assessment of Lung Edema (RALE) score 1

The patient was placed in the prone position and oxygenated at high flow with a non-rebreather mask with flow between 10 and 15 liters per minute until reaching $100 \% \mathrm{FiO}_{2}$. Additionally, respiratory therapy consisting of deep inspiration with an inspiratory hold technique was started. Epinephrine and magnesium sulfate were administered as a bronchodilator regimen (Table 2).

\section{Case 4}

A 39-year-old male COVID-19 positive patient with no significant past medical history came to the ER due to respiratory distress.

Upon admission, the patient underwent laboratory and imaging tests due to the suspicion of SARS-CoV-2 bronchospasm. Arterial blood gases were unremarkable [pH: 7.39 (normal range = 7.35-7.45), $\mathrm{PaCO}_{2}: 31$ (normal range $=33-45 \mathrm{mmHg}$ ), $\mathrm{PaO}_{2}: 63$ (normal range $\left.\left.=75-105 \mathrm{mmHg}\right)\right], \mathrm{FiO}_{2}$ of 21 (normal range $=>68 \%$ ), $\mathrm{PaO}_{2} / \mathrm{FiO}_{2}$ was 104 (normal range $=>300$ ) and an $\mathrm{O}_{2}$ saturation of $89 \%$.

Chest X-ray showed bilateral ground-glass pattern, RALE score 2 (Figure 4) [7]. The SOFA score was 3 and APACHE score was 9 (Table 1). The patient was diagnosed with ARDS. 


\section{Cureus}

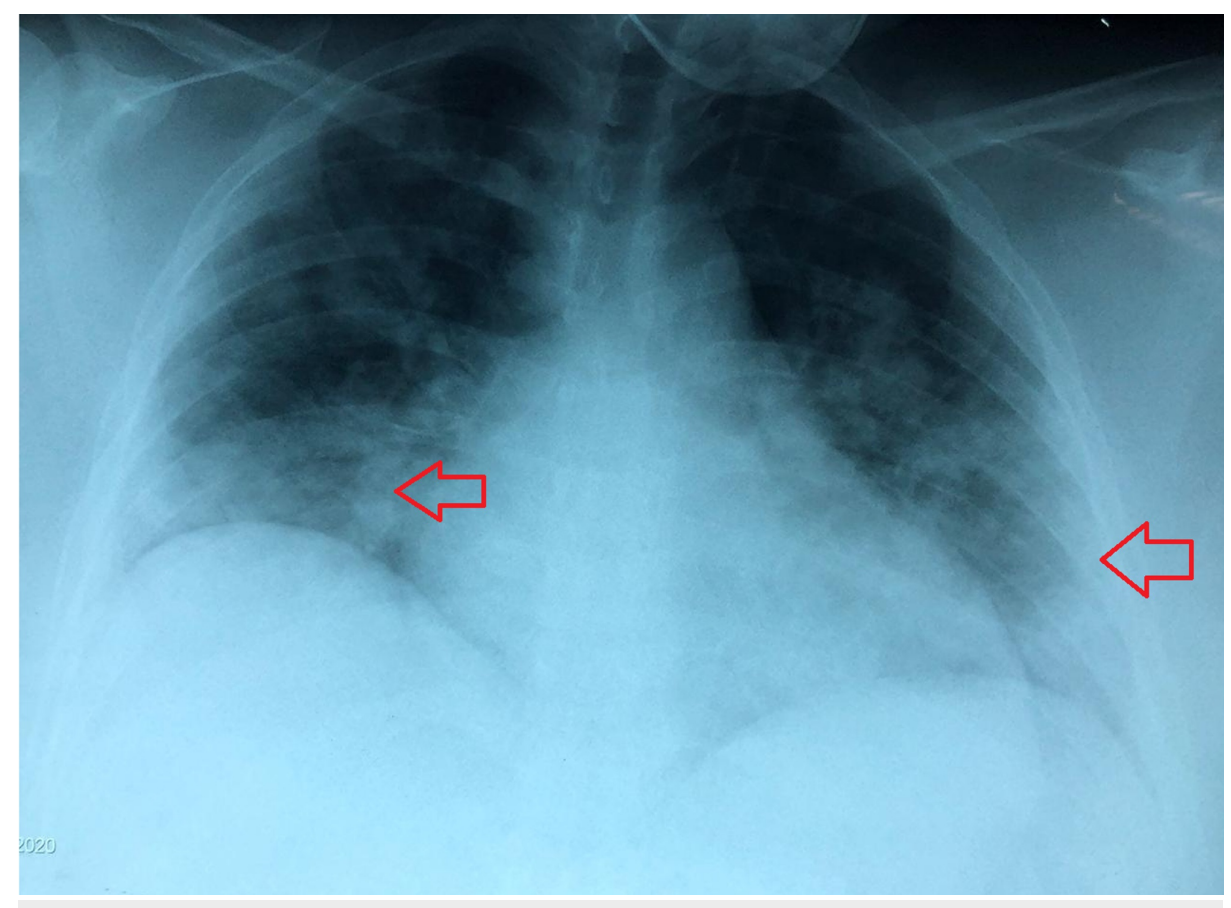

\section{FIGURE 4: Radiographic assessment of lung involvement}

Anteroposterior chest X-ray at the time of acute bronchospasm with Radiographic Assessment of Lung Edema (RALE) score 2

As part of the therapeutic approach, the patient was placed in a prone position with a non-rebreather mask with high flow oxygen between 10 and 15 liters per minute until reaching $100 \% \mathrm{FiO}_{2}$. Respiratory therapy consisting of deep inspiration with an inspiratory hold technique was started. Also, epinephrine and magnesium sulfate were administered as a bronchodilator regimen (Table 2).

\section{Discussion}

A consensus for acute bronchospasm associated with SARS-CoV-2 infection is the use of mechanical ventilation [8]; however, Zareifopoulos warns of the lack of evidence about the long-term benefits in patients on IMV [4].

To improve ventilatory mechanics and ultimately postpone the need for IMV due to acute bronchospasm in patients diagnosed with COVID-19, we put in place a therapeutic approach consisting of early respiratory therapy and pharmacological bronchospasm rescue approach.

The patients were placed in a prone position during the treatment of the acute episode of bronchospasm. As per, this maneuver could improve $\mathrm{PaO}_{2} / \mathrm{FiO}_{2}$ improving the oxygenation and ultimately postponing the need for mechanical intubation [8]. Theoretically, greater homogeneity in ventilation decreases ventral alveolar distention or dorsal collapse [9].

Concomitantly, early respiratory therapy using deep inspiration with an inspiratory hold technique was initiated. In this technique, the patient is asked to perform a forced expiration followed by deep inspiration which is held for five to seven seconds. The technique was repeated for four cycles of five breaths every hour to improve ventilation and the mobilization of secretions. Although Lazzeri reports the risk of superinfections as a possible complication of respiratory therapy in patients positive for SARS-CoV-2, this event did not occur in our patients [10].

The patients in our study developed their initial episode of severe bronchospasm, based on clinical signs and laboratory tests, at different times of their hospitalization. The events were successfully controlled through the implementation of pharmacologically preventive and rescue therapy for bronchospasm with ipratropium bromide, adrenaline, and magnesium sulfate according to the guidelines for Asthma and Chronic Obstructive Pulmonary Disease (Table 2) [11-13].

Due to the favorable evolution of the patients (20\% improvement in respiratory function values in the first four hours compared with the baseline) this therapeutic regime was maintained until the acute presentation resolved. It is worth mentioning that clinical improvement didn't correlate with radiological improvement. 


\section{Cureus}

As all patients showed remarkable improvement in ventilatory effort evidenced by the use of accessory musculature, oxygen saturation, and Kirby index $\left(\mathrm{PaO}_{2} / \mathrm{FiO}_{2}\right)$, they were discharged from ICU and continued management in the medical floors.

We remark the importance of this case report in the management of patients with severe bronchospasm associated with COVID-19 as the patients who underwent this therapeutic approach didn't require mechanical ventilation within 72 hours after the acute event. By deferring the use of invasive mechanical ventilation, we have significantly decreased the mortality of patients with ARDS secondary to SARS-CoV-2 admitted to the Intensive Care Unit in our hospital.

\section{Conclusions}

The therapeutic bundle of early respiratory therapy, consisting of deep inspiration with inspiratory hold, and pharmacological bronchospasm rescue decreased the need for invasive mechanical ventilation in patients with bronchospasm associated with SARS-CoV-2 and reduced the mortality rate. We suggest further research studies to standardized this management and implementation of guidelines.

\section{Appendices}

\begin{tabular}{|c|c|c|c|c|c|c|c|c|c|c|c|c|c|c|c|}
\hline Temperature $\left({ }^{\circ} \mathrm{C}\right)$ & MAP & HR & RF & $\mathrm{PaO} 2(\mathrm{mmHg})$ & pH & $\mathrm{Na}(\mathrm{mEq} / \mathrm{L})$ & $K(\mathrm{mEq} / \mathrm{L})$ & Crea (mg/dL) & Hto (\%) & Gcs & $\mathrm{PaO}_{2} / \mathrm{FiO}_{2}$ & Diuresis & TB (mg/dL) & Platelets $\left(\times 10^{3 / \mu L}\right)$ & Vasoactive \\
\hline 37.2 & 71 & 85 & 30 & 55 & 7.41 & 130.2 & 4.1 & 0.96 & 47.8 & 15 & 96 & 850 & 0.7 & 233000 & NO \\
\hline 36.8 & 80 & 91 & 30 & 65 & 7.34 & 138.7 & 4.5 & 1.04 & 45.4 & 15 & 115 & 1250 & 0.56 & 428000 & No \\
\hline 36.2 & 63 & 109 & 47 & 32 & 7.26 & 143.4 & 4.08 & 0.56 & 41.7 & 15 & 120 & 1500 & 0.49 & 620000 & No \\
\hline 36.2 & 65 & 125 & 35 & 71 & 7.35 & 145 & 3.7 & 0.47 & 41.6 & 15 & 180 & 1300 & 0.27 & 399000 & NO \\
\hline 37.1 & 62 & 99 & 29 & 63 & 7.39 & 142.5 & 4.9 & 0.58 & 48 & 15 & 104 & 1250 & 0.44 & 296000 & No \\
\hline 36.3 & 70 & 102 & 35 & 66 & 7.38 & 124.2 & 5.3 & 0.99 & 45 & 15 & 228 & 1000 & 0.61 & 317000 & No \\
\hline
\end{tabular}

TABLE 3: Vital signs and laboratory workup during the acute episode of bronchospasm.

MAP: Mean Arterial Blood PressurE. HR: Heart Rate. RF: Respiratory frequency. PaO2: Partial pressure of oxygen. Crea: Creatinine. Hto: Hematocrit. GCS: Glasgow Coma Scale. PaO2/FiO2: arterial oxygen pressure/inspired fraction of oxygen. TB: Total Bilirubin

Pharmacological treatment

Ipratropium bromide

Adrenalin(1:10000)

Magnesium sulfate
2 puff every 20 minutes for one hour followed by once every 6 hours

$0.03 \mathrm{mg}$ intravenously every 8 hours

2 gr every 8 hours

TABLE 4: Acute Pharmacological treatment for acute bronchospasm

\section{Additional Information \\ Disclosures}

Human subjects: Consent was obtained by all participants in this study. Conflicts of interest: In compliance with the ICMJE uniform disclosure form, all authors declare the following: Payment/services info: All authors have declared that no financial support was received from any organization for the submitted work. Financial relationships: All authors have declared that they have no financial relationships at present or within the previous three years with any organizations that might have an interest in the submitted work. Other relationships: All authors have declared that there are no other relationships or activities that could appear to have influenced the submitted work.

\section{References}

1. Hallo A, Rojas A, Hallo C: Perspective from Ecuador, the second country with more confirmed cases of coronavirus disease 2019 in South America: a review. Cureus. 2020, 12:e7452. 10.7759/cureus.7452 
2. Lai CC, Shih TP, Ko WC, et al.: Severe acute respiratory syndrome coronavirus 2 (SARS-CoV-2) and coronavirus disease-2019 (COVID-19): the epidemic and the challenges. Int J Antimicrob Agents. 2020, 55:105924. 10.1016/j.ijantimicag.2020.105924

3. Yao W, Wang T, Jiang B, et al.: Emergency tracheal intubation in 202 patients with COVID-19 in Wuhan, China: lessons learnt and international expert recommendations.. Br J Anaesth. 2020, 125:e28-e37. 10.1016/j.bja.2020.03.026

4. Zareifopoulos N, Lagadinou M, Karela A, et al.: Intubation and mechanical ventilation of patients with COVID- 19: what should we tell them?. Monaldi Arch Chest Dis. 2020, 90:1. 10.4081/monaldi.2020.1296

5. Sohrabi C, Alsafi Z, O'Neill N, et al.: World Health Organization declares global emergency: a review of the 2019 novel coronavirus (COVID-19). Int J Surg. 2020, 76:71-76. 10.1016/j.ijsu.2020.02.034

6. Shanmugaraj B, Siriwattananon K, Wangkanont K, et al.: Perspectives on monoclonal antibody therapy as potential therapeutic intervention for Coronavirus disease-19 (COVID-19). Asian Pac J Allergy Immunol. 2020, 38:10-18. 10.12932/AP-200220-0773

7. Wong HY, Lam HY, Fong AH, et al.: Frequency and distribution of chest radiographic findings in COVID-19 positive patients. Radiology. 2019, 296:E72-E78. 10.1148/radiol.2020201160

8. Winck JC, Ambrosino N: COVID-19 pandemic and non invasive respiratory management: every Goliath needs a David. An evidence based evaluation of problems. Pulmonology. 2020, 26:213-220. 10.1016/j.pulmoe.2020.04.013

9. Price S, Singh S, Ledot S, et al.: Respiratory management in severe acute respiratory syndrome coronavirus 2 infection. Eur Heart J Acute Cardiovasc Care. 2020, 9:229-238. 10.1177/2048872620924613

10. Lazzeri M, Lanza A, Bellini R, et al.: Respiratory physiotherapy in patients with COVID-19 infection in acute setting: a position paper of the Italian Association of Respiratory Physiotherapists (ARIR). Monaldi Arch Chest Dis. 2020, 90:1. 10.4081/monaldi.2020.1285

11. Reddy AP, Gupta MR: Management of asthma: the current US and European guidelines. Adv Exp Med Biol. 2014, 795:81-103. 10.1007/978-1-4614-8603-9 6

12. Jouneau S, Chabot F, Roche N: New guidelines for acute COPD exacerbations . Rev Mal Respir. 2017, 34:279281. 10.1016/j.rmr.2017.05.001

13. Ko FW, Chan KP, Hui DS, et al.: Acute exacerbation of COPD . Respirology. 2016, 21:1152-1165. 10.1111/resp. 12780 